\title{
Semblanza del sabio popular anónimo
}

\author{
Gastón Soublette Amussen \\ Instituto de Estética, Facultad de Filosofía, Pontificia Universidad Católica de Chile.
}

El sabio popular anónimo es un tipo humano que ha estado presente en todas las culturas que registra la historia. Es él quien ha conservado, cuidado y trasmitido la sabiduría que ha sido el soporte de los usos y costumbres de las comunidades populares, especialmente campesinas ${ }^{1}$.

El Libro de las Mutaciones, piedra fundamental de la cultura china, fue durante muchos siglos y milenios una tradición oral. Quien recogió, ordenó y dio forma al sistema de las mutaciones fue el patriarca fundador de la dinastía Tchou, el rey Wen, llamado "Conde del Oeste". Sus informantes fueron en gran parte sabios anónimos, varios de ellos de origen humilde. Otro tanto ocurre con el Libro del Tao de Lao Tse, cuyo texto epigramático contiene varios refranes de uso común en la China antigua.

Y si se me permite la osadía, me atreveré a decir que hace dos mil años un anónimo carpintero de la aldea de Nazaret en Judea, se ganó la fama entre sus vecinos de ser un sabio popular de libre plática y terminó arengando a grandes multitudes de trabajadores manuales, pescadores, labriegos y artesanos, a quienes decía, según el testimonio de Lucas: "Bienaventurados vosotros porque sois pobres". A él se le atribuyen algunos refranes tales como: "Los últimos serán primeros"; "Con la vara que mides, serás medido"; "Donde se halle el cadáver, ahí se reunirán los buitres"; "Quien mata al filo de la espada, al filo de la espada muere"; "De lo que abunda el corazón, habla la boca”. Algunos de los cuales están aún vigentes en el refranero chileno.

1 Clase Magistral realizada por el Profesor Gastón Soublette el día 29 de abril de 2016 con motivo de la inauguración del año académico de la Facultad de Filosofía, Pontificia Universidad Católica de Chile 
La sabiduría oral de las comunidades campesinas se ha trasmitido a través de varios géneros del habla popular, entre los que se distinguen los refranes, sentencias, proverbios, adagios, etc. Los matices que diferencian a unos de otros son sutiles, de modo que es más práctico incluirlos a todos bajo la denominación de refranes. Y al conjunto de ellos se les llama "refranero" o "paremiología", palabra que viene de la raíz griega, paroimia, voz con la que se designaban los dichos que se oyen por los caminos. Con esto, se señala indirectamente que los refranes son de procedencia popular.

También la sabiduría popular se ha transmitido a través de la poesía cantada que en Chile denominamos "Canto a lo Poeta", y a través de los cuentos tradicionales, en los que la figura del héroe, aristocrático o popular, hombre o mujer, encarna los valores éticos que dan forma a los patrones de conducta del pueblo.

Pero el sabio popular no es solo un buen refranero, o buen narrador, o cantor a lo poeta; es algo más. Y ese algo más consiste en una mejor aproximación que el común de las personas de su entorno a la sabiduría que contiene ese conjunto de expresiones de la tradición oral. Así, se concluye que el sabio popular es un ser de excepción.

El que habla es lo suficientemente antiguo como para recordar algunas experiencias vividas en la proximidad de esos seres, pertenecientes a una especie de modelo de excelencia humana; hoy, ya casi desaparecidos. Estos eran unos caballeros ensombrerados de cierta estatura y fortaleza física; por lo general, pequeños propietarios que se distinguían, entre otras características, por su correcto modo de expresarse en castellano. Hombres de pocas palabras, pero de mucha presencia. Para nada vulgares. Hábiles en sus actos, muy queridos y respetados por la comunidad, y excelentes jinetes. Si el calificativo de caballero corresponde al guerrero de la Europa medieval, hombre de linaje noble, que cargaba con su armadura, su espada y su caballo; o después al lord inglés, que gustaba montar en animales de fina sangre; o, por último, al patrón de fundo chileno, don Eyzaguirre, don Larraín, don Tocornal; estos otros, a pesar de ser de extracción popular, también eran merecedores del calificativo, montados en su caballo favorito y vistiendo su larga manta. Sus nombres pertenecían a un repertorio onomástico caído en desuso: Don Artemio, don Emeterio, don Narciso, don Evaristo. Si eran mujeres, sus nombres podían ser doña Eudocia, doña Miguelina, doña Evangelina.

Al clasificar por temas y categorías los refranes del pueblo, se puede encontrar en ellos un conjunto de características que constituyen el modelo humano que la sabiduría oral propone a la comunidad. Estas características, al añadirse una a otra, van haciendo cada vez más nítida la fisonomía de este tipo humano, hasta concluir en el ideal que los mismos dichos populares llaman un "hombre completo".

El refrán que a él se refiere dice: "Para el hombre completo son mis respetos".

No hay explicación adicional que nos aclare qué se entiende aquí por "hombre completo". Es para nosotros una proposición abierta que solo podemos entender en referencia a otras características del sabio popular destacadas en otros dichos. 
Cabe recordar, a este respecto, que Carl Gustav Jung acunó un célebre refrán: "Prefiero ser completo que bueno".

En el contexto de su pensamiento, está claro que el célebre psicólogo se está refiriendo al proceso de individuación por el cual el hombre integra y unifica las partes disociadas de su unidad interior: el ánimus, paterno, creativo, que se une al ánima, materna, receptiva; de este modo, asume y enfrenta su doble negativo denominado "sombra" y desmantela su falsa identidad, llamada "persona" o máscara, para devenir un ser auténtico.

Traigo a colación aquí este tema, porque algo de todo eso se transparenta en el conjunto de características que para la sabiduría popular constituye el hombre completo antes mencionado. Pero, para evitar el escándalo, conviene aclarar que si Jung prefiere ser completo que bueno, él no se está refiriendo a la verdadera bondad, sino a la pobre bonhomía del pusilánime que vive haciendo concesiones que atentan contra su dignidad, so pretexto de parecer grato a los demás.

Las características que en su conjunto integran la figura del sabio popular empiezan por la sabiduría misma, de la cual un refrán dice: "El árbol de la vida es la sabiduría".

Esta afirmación de tono tan subido procede del Génesis de la Biblia Hebrea, en cuyos primeros capítulos se menciona un árbol que estaba en el centro del paraíso, junto al árbol maligno de la ciencia del bien y del mal, cuyo fruto, según el decir de Dios, causa la muerte. El árbol de la vida aparece como la contraimagen del árbol maligno, y se dice que comer de su fruto permite vencer la muerte. Según el uso que se hace de la palabra "muerte" en la Biblia, se entiende que en muchos pasajes se está aludiendo a la muerte espiritual, aquella que transforma al hombre en un muerto viviente. El sabio popular también es consciente de que hay hombres que pueden morir interiormente, tal como lo demuestra su refrán: "Hay vivos que parecen muertos / Y hay muertos que aún viven".

La segunda parte de esta reflexión se refiere a aquellos sujetos que mientras vivieron realizaron algo tan valioso para la comunidad que dejaron una huella que perdura. Con esta aclaración, se entiende que el sabio popular está queriendo decir que mediante la sabiduría, el hombre puede evitar que su luz interior se apague, cayendo en la inconsciencia y la insensatez. Y es esta última palabra la que nos da la clave para entender lo que es en sí eso que tradicionalmente llamamos "sabiduría", esto es, un conocimiento vivencial que nos enseña el sentido de la vida, a diferencia de la ciencia, que solo se ocupa de los fenómenos.

Siguiendo esta línea de pensamiento, surge otro refrán referido a la sabiduría, con el que el sabio popular establece una distinción entre las meras ocurrencias humanas, de cualquier tipo, y por otra parte, un comportamiento verdaderamente sensato, entendiendo así que no siempre nuestras ocurrencias, creaciones y realizaciones se apoyan en la sabiduría. Ese refrán dice: "La poca sabiduría empaña las ocurrencias".

Esta es una distinción muy iluminadora a la hora de juzgar los actos de hombres geniales que han causado daño a la humanidad. Por ejemplo, aquel hombre que pasa por 
ser el más inteligente del siglo xx, quien dio los fundamentos teóricos para la fabricación de la bomba atómica, con su célebre fórmula $\mathrm{E}=\mathrm{MC}^{2}$. Energía igual Masa por velocidad de la luz al cuadrado. Es interesante saber que este hombre inteligente se alcanzó a dar cuenta de su insensatez al recomendar el uso de su fórmula para aplicarla al armamento en plena guerra mundial. Se sabe que al respecto dijo: "Todos me llaman sabio, pero deben saber que no lo soy; el sabio es Gandhi, porque él conoce a los hombres".

El sabio popular tiene la sutileza de pensamiento para percibir la diferencia, y esto seguramente por la forma como ciertos inteligentes del país intervinieron en la trama cultural de las comunidades campesinas de un modo que a nuestros sabios les pareció insensato.

Para el sabio popular, el vivir con sabiduría es un arte que se puede aprender, de ahí el refrán que dice: "Cuando aprenda a vivir quiero morir".

Vale decir, no quiero que la muerte me sorprenda sin haber vivido en consciencia conforme con lo que mi corazón me dice claramente que es sensato y con lo que me dice que no lo es, pues para el sabio popular: "El corazón no miente a nadie".

En lo que se refiere a la virtud, la inteligencia con que el sabio popular aborda esta cuestión es sorprendente: "La virtud es divina, la moral es humana".

Si entendemos por virtud la espontánea inclinación de un hombre a amar a su prójimo y a obrar rectamente como una característica constitucional de su ser, entonces la virtud es un don, y ese don procede de la misma fuente que lo trajo a la vida.

En segundo término aparece la moral, bastante desmedrada, porque no es difícil percibir que, con respecto a la virtud, la moral existe para cubrir el déficit de aquella. Esto es obrar como si se tuviera virtud sin tenerla, compulsivamente. Por eso es que la moral se quiebra con tanta facilidad. Y esta distinción no es frecuente que se haga. Ni siquiera la Iglesia en su cruzada moralizadora de otras décadas - un tanto fastidiosa, hay que decir por lo demás- nunca, que yo sepa, hizo esa distinción, que para muchos resulta muy iluminadora y pone el dedo en la llaga, como se dice vulgarmente.

Relacionado al tema de la virtud, encontramos esta otra reflexión: "Donde reina el amor, sobran la leyes".

La situación descrita aquí es una utopía. Y da la impresión de que el sabio popular al concebirla está como formulando una interrogante tácita semejante a la que formuló el padre Jorge Costadoat en un artículo de tema teológico que publicó en la revista "Artes y Letras", de El Mercurio: “¿Y qué fue del Reino de Dios?”

Pregunta por demás desafiante. Difícil de responder sin meterse "en honduras y camisas de once varas", como dice el refrán.

¿Una utopía donde el amor reemplaza a las leyes? Para esto escuchemos mejor lo que nos dice el sabio chino Lao Tse:

Mientras más reglamentos y prohibiciones hay

tanto más se empobrece el pueblo.

Mientras más eficiencia hay

tanto más sumido en el desorden se halla el Estado. 
Mientras más actúa la gente con habilidad y astucia tantos más signos nefastos aparecen.

Mientras más leyes y decretos se promulgan

tantos más ladrones y bandidos surgen.

Sin querer ofender las convicciones de nadie y conforme al derecho que me da la ancianidad, me atrevo a decir que este es un retrato del Chile de hoy.

¿Cómo es, entonces, que el sabio popular pudo imaginar un mundo donde el amor hace innecesarias las leyes? ¿De dónde procede esa utopía? Sin duda procede del Evangelio y se denomina Reino de Dios. Pero cabe preguntarse si en su experiencia de vida, el sabio que acuñó ese refrán conoció alguna comunidad virtuosa en la que la gente se amaba, se respetaba y procedía con solidaridad, y si habría sido en base a esa realidad que él vislumbró un mundo virtuoso en el que las leyes sobran. Lo más probable, sin embargo, es que esta reflexión no pase de ser más que una buena utopía. Esta, de cualquier modo, contiene una verdad que no puede evitar la interrogante " ¿Y qué fue del reino de Dios?". Quizás por todo esto, en los refranes que nuestro sabio acuñó para referirse a los administradores de la fe, fue tan irreverente...

Pasemos a otra característica del sabio popular, quien, como en toda tradición sapiencial, en sus dichos incluye algunas referencias al conocimiento de sí mismo, que es como el fundamento mismo de la sabiduría.

Aquello que en la antigüedad fue una invitación, una exhortación o imperativo ético, como el célebre "Conócete a ti mismo" del santuario de Delfos, en el lenguaje popular deviene casi una sentencia condenatoria, en los siguientes términos: "Quien a sí mismo no se conoce, a sí mismo se asesina”.

No sería del todo aventurado pensar que tal énfasis en este imperativo, que pone el acento en las consecuencias que se siguen del hecho de no conocerse, tenga su origen en el mestizaje, pues a partir del mapudungun, y de los aforismos sapienciales que se han recogido de la tradición oral mapuche, se puede inferir que para los antiguos, si hay una cualidad que ellos apreciaban en el hombre, era el "despertar", el estado de alerta psicológico: en la lengua mapuche, hay catorce formas verbales que apuntan en este sentido. Lo peor que podía ocurrirle a un hombre era la atrofia, por pereza o indolencia, de su entendimiento para consigo mismo; el sujeto tiene el imperativo de trabajar sobre su autoconocimiento.

Las jerarquías que establece ese despertar de la conciencia se expresan poéticamente en el siguiente poema de tradición mapuche.

¿En qué os habéis convertido en vuestro tránsito?

¿Os habéis hecho seres de la región del Zenith?

¿Os habéis vueltos águilas del sol?

¿Os habéis hecho peucos del sol?

¿Os habéis hecho cernícalos del sol?

¿O sois apenas moscas azules en vuestro tránsito? 
Las águilas del sol, los seres de la región del Zenith, se elevan a lo más alto, como buscando la fuente de la luz, pero las moscas azules solo se alimentan de carroña y excremento.

No será necesario explicar aquí que la posibilidad o imposibilidad del conocimiento de sí mismo se debe a que el ser consciente actúa y piensa sobre una amplia base inconsciente, cuyos contenidos no manifiestos emergen al presionar la consciencia gradualmente o, en algunos casos, al irrumpirla de manera brusca, comprometiendo nuestra responsabilidad por lo que resulte de esas emergencias.

La segunda parte del refrán antes comentado califica en términos extremadamente graves nuestra indolencia en este quehacer, quizás el más importante de la vida, pues el hombre que no se enfrenta a sí mismo, ni conoce la experiencia de sondear su consciencia, se convierte en presa de sus impulsos, lo que puede hasta acarrearle la muerte.

Ese sondear la consciencia el sabio popular lo llama "conocer su corazón”, asiento de la consciencia y de la mente; centro de la yoidad, según el yoga hindú. Por eso, el sabio popular advierte: "El corazón no miente a nadie".

Del contexto de esta tradición, se infiere que el corazón ve, siente y presiente. Su percepción es instantánea, porque es la fuente de la intuición. En la paremiología chilena, el hombre que conoce su corazón es descrito así: "Quien conoce su corazón, desafía sus ojos".

Los ojos ven la apariencia del mundo y de los demás hombres. Para quien no se conoce a sí mismo, esa percepción de la apariencia es suficiente conocimiento del mundo. Pero si quien conoce su corazón, desafía sus ojos, es porque entiende que tras la apariencia hay todo un mundo por conocer, y hay que estar alerta, porque "la vista engaña", como dice el huaso.

El siguiente refrán se refiere directamente a la apariencia de las personas: "Mejor dame raza que buena traza”.

Aquí, la palabra raza es una metáfora de la calidad humana. Se la ha usado además en el supuesto de que esa calidad también puede haber sido heredada de sus abuelos. La traza es solo la apariencia.

Sobre la objetividad de visión que requiere la experiencia de lo real, hay un refrán notable que dice: "El ojo verá bien siempre que la mente no mire por él". Es una consecuencia del autoconocimiento que permite ver más allá de la apariencia y rechazar un juicio cargado de subjetividad.

Cabe preguntarse, a propósito de estos dichos referentes al conocimiento de sí mismo, si de algún modo nuestros sabios populares tuvieron un acceso espontáneo a eso que los orientales llaman meditación, es decir, la integración de la consciencia consigo mismo hasta alcanzar un estado libre de contenido. Por lo que recuerdo haber visto con mis propios ojos, los momentos de reposo de aquellos caballeros campesinos, que podían permanecer inmóviles largo tiempo en su pequeño huerto a la caída de la tarde, sin necesidad de hablar con nadie más que su ser interior, sea lo que sea lo que 
les ocurría; esa paz del ánimo era su meditación. Quizás de ahí surgieron las siguientes reflexiones: "Nadie sabe lo que tiene"; "Valemos mucho más por más que digan".

Así, quizás, vivieron la excepcional experiencia de extraer de sí mismos lo mejor de su ser. Lo que explicaría esta otra reflexión. "Si eres sabio, ríe".

Lo dicho sobre el conocimiento de sí mismo, sin embargo, podría inducirnos al error de pensar que este saber se genera solo por un movimiento de la conciencia sobre sí mismo. El sabio popular, hombre hábil en sus actos, nos enseña que ese conocimiento se obtiene también mediante la acción, enfrentando los desafíos directos de la existencia.

Da la impresión de que los sabios populares anónimos de cualquiera cultura son el mismo personaje y cumple en la comunidad la misma función. Incluso un hombre de tan alta autoridad espiritual como Confucio nos habla de este aspecto de la sabiduría en los mismos términos, como si fuera un jefe de familia de cualquier estamento de la sociedad. A este respecto Confucio enseña: cuando un sabio de la antigüedad quería poner orden en su casa, ponía orden en sus pensamientos; para poner orden en sus pensamientos, ponía orden en su corazón; para poner orden en su corazón, escrutaba los móviles ocultos de sus propios actos (Libro del Ta Hio).

El sabio popular chileno nos dice lo mismo pero mediante hermosas rnetáforas poéticas: "Para saber quién es, canta el canario".

Con esta reflexión, el sabio popular nos está diciendo que el hombre se hace haciendo y que el acto de conocerse a sí mismo pertenece originalmente a la economía psíquica de todos los hombres.

En lo que se refiere a la introspección, Confucio enseña que ese sondeo profundo de nuestra propia esencia es el que nos capacita para conocer la interioridad de los otros hombres, pues solo una experiencia profunda de nosotros mismos es lo que garantiza una experiencia profunda del otro. Hay varios refranes populares que apuntan a eso, pero el mejor que conozco fue acuñado por un sabio popular chileno, que excepcionalmente se hizo famoso en todo el mundo y hasta ganó el premio Nobel de Literatura: Neftalí Reyes Basoalto, Pablo Neruda. En su Memorial de Isla Negra el poeta nos dice: “Quien descubre el quién soy descubrirá el quién eres".

Son los primeros versos de su poema La Injusticia. La primera estrofa en su totalidad dice así:

Quien descubre el quién soy descubrirá el quién eres.

Y el cómo y el adónde.

Toqué de pronto toda la injusticia.

El hambre no era solo el hambre,

sino la medida del hombre.

El frío, el viento, eran también medidas.

Midió cien hambres y cayó el erguido.

A los cien fríos fue enterrado Pedro.

Un solo viento duró la pobre casa. 
En el grupo de estos dichos de sabiduría popular referentes a la inteligencia, hay uno que conviene distinguir sobre los demás. Dice así: "Al más sabio se le va una punta".

Lo cito para destacar una característica muy especial de la sabiduría popular. Me refiero al punto en que este sabio está situado para conocer el mundo y los hombres. Tiene que ver con el hecho de tratarse de alguien que no aspira a cambiar de status, cuya imagen de sí mismo no se proyecta a un futuro concebido en términos de prosperidad material. El no ser un pensador profesional, un académico, lo define como un tipo humano que está contento con lo que es y con lo que hace y con lo que tiene, está contento de que su familia sea lo que es. Se entiende, claro está, que su pobreza es relativa, pues por lo general a estos caballeros sabios del estamento campesino chileno no les faltaba nada. Por esa condición de hombres armónicamente insertos en el orden natural, los sabios estaban libres de la tensión psicológica que conlleva la ambición de crecer y hacer fortuna. Libres también del espíritu de competencia, y del bullicioso enjambre de la gran ciudad, y del peso permanente de la información por la que nuestra existencia es visualizada como un flujo paralelo al acontecer de un orden extenso y ajeno. Esa situación de existencia localizada evitaba que su pensamiento especulara más allá de su condición real y operante como habitante de la tierra, por eso su experiencia del mundo, a juzgar por lo que dicen sus humildes reflexiones y comentarios del vivir, era muy completa y equilibrada.

Mirada desde esa perspectiva, los sabios vivían en una situación privilegiada para ver por dónde fallaba la sabiduría de los estudiosos y entendidos. El hecho de atreverse a decir: "La poca sabiduría empeña la ocurrencia", para el caso de Einstein, resulta particularmente pertinente.

Sobre este particular conviene leer pasajes del Libro Rojo de Carl Gustav Jung, recientemente publicado, donde al autor desarrolla toda una crítica para dejar en evidencia por dónde falla el saber de la alta cultura, y por ende, ese héroe al que los occidentales siempre hemos rendido un culto que no admite apelación: el genio. La misma posición del chino Lao Tse, el único sabio anterior a Jung que se atrevió a poner al genio en el banquillo de los acusados. En este mismo sentido, sería interesante seguirle la pista al pensamiento evangélico y al de los escritos apostólicos, especialmente al de las cartas del apóstol Pablo donde él adopta una posición similar.

No sabemos cómo el sabio popular procesó interiormente sus reflexiones frente al estamento ilustrado de la nación y a las figuras de los reconocidos como superdotados. El hecho es que en referencia a ese mundo que trasciende su dimensión de vida, él concibió este extraño pensamiento: "Todo sabio tiene a un loco por hermano".

Es probable que lo que busca expresar esta trágica reflexión ha sido concebido en términos metafóricos, en el sentido de que para la sabiduría popular el mucho saber de los que son reconocidos como sabios, mirado desde la perspectiva de una visión de mundo generada en una vida armonizada con el orden natural, puede aparecer como locura.

Aunque también, desde la perspectiva de la psicología analítica de Jung, esto de que todo sabio tiene a un loco por hermano, puede ser algo que se ha dado en la 
realidad, pero como la proyección de un fenómeno sincronístico; es decir, demasiada concentración de luz en un hombre es un exceso que genera violencia en la trama vital de la sociedad y esa violencia la pagan los de su entorno, lo cual se explica por la vía del inconsciente colectivo. El caso más notable en ese sentido es el del Buda, quien efectivamente tuvo a un loco por hermano.

A modo de ejemplo de cómo el sabio popular concibe la inteligencia, cito el siguiente refrán: "El necio no ve el mismo árbol que el sabio".

El sentido de estas palabras se aclara en atención a otros dichos que se refieren al árbol como símbolo del orden. Por ejemplo, el ya citado al comienzo: "El árbol de la vida es la sabiduría", o este otro: "Vivimos sobre nuestras raíces, no sobre nuestras ramas". Eso es lo que ve el sabio cuando mira el árbol, además de todo lo que el árbol es en sí para cualquiera que sea capaz de apreciar su belleza, la utilidad de su sombra y la función que cumple en la protección de los manantiales. Pero aunque no se diga qué ve el necio cuando mira un árbol, resulta evidente que como todo chileno normal solo ve recursos naturales, esto es, un complejo maderero para negociar...

En lo que se refiere a las raíces y las ramas, se entiende fácilmente que el sabio proclama que el fundamento del orden es invisible, espiritual; y que todo el entramado de instituciones y creaciones de una cultura simbolizada en el ramaje es el complejo existencial en que se diversifica la vida de la comunidad.

A la virtud de la humildad, el sabio popular le dedica una atención especial, aunque, por tratarse de una sabiduría en la que orden natural impone su paradigma inconscientemente, la humildad a la que suele referirse esta tradición oral, no es un sacrificio ascético, ni una autocensura, ni un castigo al yo autorreferente, como se verá a continuación.

La palabra "humildad" procede del latín humilitas, la que a su vez procede de la voz humus, que significa tierra. Ante los dos demiurgos antiguos fundamentales del Cielo y la Tierra, al hombre le correspondía adoptar una actitud de humildad frente a sus designios, pues él era hijo de la Tierra por tener un cuerpo que volverá a la Tierra y que se transformará en Tierra otra vez. La humildad de los sabios antiguos tenía un fundamento cósmico. Pero ese mismo hombre era también un hijo del espíritu, de lo inmaterial, que corresponde al ámbito del Cielo. Así se establecía en el deber ser el imperativo de reducir las exigencias del ser aparente, exterior o carnal, para que pudiera manifestarse el ser interior esencial. El diccionario de la Real Academia define esta virtud solo como conciencia de nuestras limitaciones y el obrar que se sigue de esa comprensión, lo cual es poco decir.

Conforme a lo dicho antes, la humildad pertenece también a la economía psíquica originaria del hombre. El sabio popular, por su parte, se refiere a esta virtud en términos gloriosos: "La humildad es el hilo con que se encadena la gloria".

La palabra "hilo" aquí es clave. Las características del hilo -su delgadez junto a su desproporcionada longitud- nos están enseñando cómo avanzar hacia una meta distante, reduciendo a nada las exigencias del ego. La palabra "encadena” está aquí 
solo para indicar una vía que se recorre por etapas sucesivas. El término del proceso es la gloria, palabra que tiene un significado relacionado con la salvación religiosa; la gloria es el cielo adonde van los justos. Pero su significado podría también bajar de esas alturas y dar cuenta de la recompensa que la vida misma da a los hombres sabios que han sabido mantenerse en la humildad.

En el Libro de las Mutaciones de China, esta actitud, en un hombre que tiene peso específico interior, por sincronicidad, le abre un camino de realización. Y es en ese tratado de dialéctica natural que la humildad del sabio aparece fundada en la polaridad universal de Cielo y Tierra.

El Mahatma Gandhi, cuando se dio cuenta de que de hecho había llegado a ser el líder indiscutido de su pueblo, escribió en su autobiografía: "Si tal es mi condición actual, mi deber es hacerme nada".

Esta apología que el sabio popular hace de la humildad tiene también un fundamento escritural, pues son palabras de Jesucristo las que dicen: "Quien se humilla será ensalzado". Aunque en la sabiduría popular no se trata específicamente de humillarse, a modo de una penitencia, sino simplemente estar situado en la humildad como una actitud básica y permanente del comportamiento.

Como contraparte de la humildad, abundan los refranes que condenan la soberbia: "No hay altanería que no amanezca caída"; "Más vale vivir sin alas que morir de un pechugazo"; "Lo que con fuerza empieza suele no ser durable"; "Quien sube como palma, cae como coco"; "El que sube a mayores suele quedar en menores"; "El que se viste con ropa ajena, en la calle lo empelotan".

Nótese que este último, tan chileno en su decir, con otras palabras figura en un capítulo del Libro de las Mutaciones de Confucio, en referencia al hombre que sube a un alto puesto, solo por medio de maniobras astutas y sin merecimiento. Ahora anda en carro, pero los ladrones no dejarán de advertir que este se ha echado encima lo que no merece y fatalmente se lo arrebatarán.

Y con esto tocamos un punto importante de la sabiduría popular; me refiero a la intuición que todo sabio popular y todo indígena han tenido de la existencia de un mecanismo universal de correspondencias analógicas que obran por resonancia. Ya en el refrán de procedencia evangélica, "Con la vara que mides, serás medido, se insinúa la existencia de esa ley, como también en: "Quien a hierro mata, a hierro muere". Todo esto explica bien el principio de sincronicidad descubierto por Jung justamente en el estudio de la sabiduría indígena y en el trasfondo psicológico del sistema chino de las mutaciones.

Según el principio de sincronicidad al hombre en su existencia le ocurrirán hechos que tienen una relación analógica con los contenidos más profundos de su psique. Incluso algunos sucesos aparentemente casuales como el canto o la aparición de ciertos pájaros, son señales que simbólicamente se proyectan en el acontecer y que la comunidad, por larga tradición, reconoce como tales. El siguiente refrán es un dicho clásico referido a este fenómeno: 


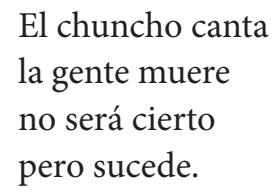

El pasaje en que dice "no será cierto" es una concesión que el sabio popular hace a la lógica imperante, impuesta por el estamento ilustrado de la nación.

Jung estudió estos fenómenos paranormales, especialmente este de los pájaros que cantan cuando alguien muere o que visitan a personas relacionadas por amistad o afecto con otras que han fallecido, y llegó a la conclusión de que constituían una buena prueba de su teoría del inconsciente colectivo.

Pero uno puede explicar todo esto en el plano teórico, otra cosa es cuando el fenómeno, que al parecer solo ocurre en el ámbito de la cultura popular campesina, le ocurre a una persona de la cultura ilustrada proclive a rechazar lo que racionalmente considera superstición. Fue el caso de los tres hijos del ex canciller y presidente del Senado, Gabriel Valdés, quienes sucesivamente, de mayor a menor y en un lapso de siete días después del fallecimiento de su padre, se hallaron de pronto frente a un pájaro del tamaño de un zorzal, que se paró frente a ellos, inmóvil, y sobre el mismo escritorio en que estaban trabajando. Al menor, Maximiano, le ocurrió en la ciudad del Vaticano, en un ensayo de orquesta de un concierto que Benedicto Xvi organizó para la comunidad religiosa de la Santa Sede. Cuando ya el ensayo iba a comenzar, y estando Maximiano con la batuta en la mano, hizo una pausa, porque sobre un micrófono instalado para grabar el concierto, se había posado un pájaro que nadie sabe cómo entró en la sala. Las aves eran reales y volaron cuando se las espantó con las manos.

La explicación de Jung para fenómenos como estos es sorprendente: son arquetipos arcaicos que subyacen en el inconsciente colectivo a manera de memoria genética. En este caso, se trata de la antigua creencia de que cuando el hombre muere, su alma abandona el cuerpo en forma de pájaro. Ahora bien, para que eso le ocurra a personas que no podrían dar crédito a estar rarezas, debe haber un lazo afectivo muy fuerte entre el que muere y sus familiares, como es el caso que comentamos.

Esta explicación puede entenderse intelectualmente, aunque procede de un fenómeno extraño que no se aviene con la lógica del hombre común, tanto más extraño cuanto que la proyección del mencionado arquetipo arcaico en el acontecer real no es una ilusión, sino también un hecho real.

Es normal que el hombre ilustrado piense que el pueblo campesino es supersticioso. Jung era también un hombre perteneciente a la cultura ilustrada, pero a quien campesinos ignorantes e indígenas le abrieron los ojos sobre aspectos de la realidad que la racionalidad urbana debió ignorar para instalar en el mundo su orden lógico. Por eso el célebre psicólogo tomó toda la información recibida en sus trabajos de terreno y la procesó con el método científico y logró convertir todo eso en ciencia mediante una investigación sobre la fenomenología del inconsciente. 
Es lo que Hamlet dice a su escéptico amigo Horacio: "Más cosas hay en el cielo y en la tierra de las que tú has soñado en tu filosofía".

Se trata de aspectos inéditos de la realidad que solo caben en un saber generado en una mente inserta en el orden natural. Ahora bien, de ese paradigma resulta la visión bipolar del acontecer, la dialéctica de lo creativo y lo receptivo que en sí misma establece el equilibrio de los contrarios. Es lo que tan acertadamente enseña Lao Tse en un epigrama de su Libro del Tao, que dice:

La vía del Cielo consiste

en aminorar lo excesivo

y completar lo insuficiente.

Esa ley opera en todos los ámbitos del universo, a excepción del orden humano. La segunda parte de esta reflexión continúa así:

El camino del hombre es diferente

sustrae al que tiene poco

para añadirlo al que tiene en demasía.

En relación con este tema, el sabio popular en sus reflexiones revela que también percibe el mecanismo de una justicia cósmica que equilibra lo abundante con exiguo, pero que está impedido de operar en el orden humano, pues el mismo sentido del epigrama de Lao Tse se transparenta en afirmaciones como estas: "Siempre hay uno que pierde cuando otro gana"; "No es raro que a uno le falte lo que a otro le sobra".

Da la impresión de que el pensamiento evangélico difundido por un trabajador manual, como Jesús de Nazaret, entre las masas populares de su nación, se aproxima a la misma idea. De ahí el uso que el carpintero de Nazaret hacía de la expresión "riquezas injustas" para referirse sin más a las riquezas acumuladas por los representantes del sector acaudalado de su patria. De ahí también el tenor de la primera bienaventuranza del Sermón del Monte, según la versión de Lucas: "Bienaventurados vosotros porque sois pobres".

Sus oyentes no eran mendigos obviamente, pero sí hombres de trabajo que vivían laboriosamente con lo necesario sin pretender hacer del lucro su actividad principal. Esa condición social mayoritaria, este predicador popular la consideraba normal. Y quien, perteneciendo al estamento alto, lo interrogó sobre cómo ganar la vida eterna, él terminó aconsejándole deshacerse de sus riquezas.

Otro aspecto de la sabiduría popular que conviene destacar es el respeto que el sabio popular tuvo siempre por la palabra. Si hay algo que distinguía al sabio popular era el ser hombre de pocas palabras y, a la vez, hombre de palabra. Con relación a esto vale citar el refrán que dice "Al hombre se le conoce por la palabra / y al buey por el asta".

Esta parquedad en el decir, en el Libro del Tao de Lao Tse, es mencionada en estos términos: "Hablar poco es lo natural". 
Vale decir, tal es el ritmo que imprime en nuestra mente el vivir en armonía con la naturaleza. Pues el simple hecho de ser así de los árboles, el agua, las montañas, las tierras, eso patentiza también el valor que en sí tiene la sola presencia humana. Si no hay abundancia de asuntos que atender, no hay para qué comentar. La mente no está afiebrada por una sobrecarga de información.

Pero hay detrás de esto algo más profundo. Quiero decir la palabra como instrumento por el cual determinamos la realidad, y más aún: creamos la realidad. De aquí viene el mito de la creación del Cielo y la Tierra por el Verbo de Dios. Así se entiende la importancia que en otros tiempos tenía la palabra empeñada, y sobre todo, la bendición y la maldición, como si el pensamiento formalizado en el verbo adquiriera una virtud que tiende por sí misma a realizarse. En el caso del sabio popular, se percibe que su actitud ante la palabra viene respaldada por una tradición del hablar justo y veraz, y del poder del verbo, por el cual no se malgastan las palabras, ni se violan los secretos. El siguiente epigrama mapuche nos lo hace sentir no sin cierto sagrado estremecimiento: "Revelé el secreto que guardaba / y mi espíritu vio abierta la fosa de la muerte".

El respeto de la palabra conlleva necesariamente un igual respeto por el silencio: "No hay que perder la oportunidad de quedarse callado".

Vale decir, el permanecer en silencio es un bien. En el silencio se ejerce la influencia por el ser y no por el hacer entre los hombres.

El sabio popular también demuestra estar consciente del fenómeno de la decadencia del lenguaje, cuando el respeto por la palabra se pierde y se incrementa el discurso por un habla compulsiva que reemplaza, a modo de relleno, la presencia real del hombre:

"Lo que mucho prueba, nada prueba".

"Quien mucho habla mucho yerra".

"Hay hombres vanos que tienen lengua pero no tienen manos".

"Buen hablador nunca buen hacedor".

"El leso le da mucho trabajo a la sin hueso".

Hay aquí una aguda conciencia del leguaje desvirtuado que se genera a sí mismo en un encadenamiento gratuito sin incidencia en lo real.

El tema del lenguaje va íntimamente relacionado con el tema de la verdad. Sobre esta cuestión, hay reflexiones del sabio popular que son muy reveladoras, como esta: "Quien es como parece, cumplirá lo que promete".

La primera parte de esta frase destaca al hombre auténtico, esto es, aquel cuyo exterior es congruente con su interior. Sobre este punto es interesante recordar que tal era la definición que Gandhi daba de la verdad. Para él, la verdad no era de preferencia la meta del conocimiento, sino que tenía una definición ética, esto es, la verdad es que tú seas un hombre verdadero, alguien que no aparenta ser lo que no es y que 
muestra ser lo que realmente es. Un ser transparente y confiable, que tiene el coraje de decir la verdad y no solo buscarla.

Para el sabio popular todos estamos en deuda con la verdad, por eso él la define en términos de severidad:

"La verdad es bella pero mal vestida".

Además, la verdad en el mundo sufre violencia:

"La verdad, aunque es severa, es amiga verdadera".

Hay uno solo, Jesucristo, que no tiene deuda alguna con la verdad, por eso en el Canto a lo Divino se lo llama El Verdadero.

Respecto del mundo, este es definido en los mismos términos que lo definen los escritos apostólicos del Nuevo Testamento. El mundo está fundamentado en la mentira. Por eso, "El río de la verdad corre por cauces de mentira". A su vez, este tema se relaciona con el mal, la mentira entronizada.

Finalmente, cabe relacionar al sabio popular con el mundo espiritual, aspecto de su persona que él procura equilibrar con el hecho de ser un habitante del mundo, con responsabilidades e imperativos vitales. El refrán que expresa esa búsqueda del equilibrio entre lo del Cielo y lo de la Tierra está expresado en términos por demás herméticos: "Regla y compás, cuando más, más".

Con la regla se puede construir un cuadrado y con el compás un círculo. El cuadrado es el máximo símbolo de lo mensurable. En la cosmología antigua, simbolizaba la plataforma de la tierra con sus cuatro direcciones cardinales. El círculo, al estar inscrito en una circunferencia, es un polígono de infinitos lados, y la circunferencia es lo que no tiene principio ni fin. Simboliza el Cielo, lo eterno lo inmutable y la totalidad, en cuanto no se le puede agregar nada. "Cuando más, más" significa que cualquier acento puesto en alguno de estos aspectos de la vida, exige equilibrarlo con un acento igual en el otro aspecto, para evitar el desequilibrio que se sigue de un espiritualismo excesivo que puede alterar la psique y distorsionar la realidad, o llevar a una caída en el materialismo o en un activismo alienante.

Para el final he dejado una característica del sabio popular chileno que es como la base en que se asientan las demás características, vale decir, lo que concierne a su espiritualidad pero en su relación con el ser supremo.

Las características estudiadas antes pertenecen todas a la matriz cultural del cristianismo, aunque en la paremiología chilena, y en la de cualquiera nación cristiana, no se hace una mención expresa de la persona de Cristo. Así, el refranero es monoteísta, ortodoxo y cristiano por los valores asumidos para la concepción de un modelo humano. La ortodoxia de este monoteísmo se percibe en varios refranes, como este: "Dios conmigo y yo con él / Él delante de mí y yo detrás de Él".

La primera parte de esta reflexión contiene la esencia del monoteísmo. Pues si yo puedo decir que estoy con Dios, es porque antes Dios quiso estar conmigo. Así, el padre de la fe monoteísta, Abraham, no buscó a Iahvé, es Iahvé quien lo buscó a 
él. Lo mismo ocurrió con Moisés. Por eso Jesús puntualiza a sus discípulos que fue él quien los eligió y no que ellos lo eligieron a él. Puede parecer un pequeño detalle imperceptible, pero en esta economía de palabras no hay fraseología gratuita.

La segunda parte del refrán se sigue de la primera: "Él delante de mí y yo detrás de él”.

La primera parte incide sobre el encuentro con el Ser; la segunda, el encuentro con el sentido. Él delante de mí supone el camino para que se haga su voluntad, así en la tierra como en el cielo, el cual yo debo seguir guiado por Él.

Si antes el sabio popular nos enseñó que la virtud es divina, aquí en un acto de fe fundamental confirma esa verdad:

"Dios te haga bueno, que será como hacerte de nuevo".

"Dios es la fuente de la bondad y de todo don perfecto".

Recordemos que en el evangelio de Juan un joven rico interroga a Jesús en estos términos: "Maestro, ¿qué debo hacer de bueno para alcanzar la vida eterna?" Jesús le responde: “¿Por qué me preguntas sobre lo bueno? Uno solo es el bueno”. El joven pensaba en la justificación por las obras de la Ley mosaica, y Jesús se adelanta a dejarle en claro que no hay nada en el mundo que pueda hacerte justo sino Dios. Porque los preceptos de la Ley se pueden cumplir también mecánicamente. Tal es la ortodoxia que se percibe en estas reflexiones del sabio popular. De aquí se sigue el concepto de providencia, o cuidado que Dios tiene de sus criaturas:

"A nadie le falta Dios".

"El que busca halla, aunque sea un canalla".

"Quien no pone en Dios su confianza

tendrá mala andanza”.

"El que tiene esperanza todo lo alcanza".

Pero esta ortodoxia monoteísta y bíblica del sabio popular no es compartida por toda la comunidad, porque el catolicismo ha sido proclive a multiplicar las mediaciones entre el hombre y Dios, entre otros modos, mediante el culto a los santos y las reliquias. Por eso el sabio popular le advierte a la comunidad que: "Sólo Dios es capataz, los demás son puros bueyes".

Con lo cual se entiende que él quiere poner a Dios y a los santos en el lugar que verdaderamente les corresponde, como también lo expresa este refrán: “Cuando Dios no quiere, ni todos los santos pueden". Y es esa misma pureza doctrinaria de su formación religiosa la que lo vuelve reservado y, sobre todo, crítico de la administración religiosa del clero. Los siguientes refranes son de una irreverencia evidente:

"Donde Dios tiene su iglesia, el diablo tiene su capilla".

"El cura y la suegra saben más que la culebra"

"Cuando el diablo se vuelve viejo, se mete a fraile".

"Diablo encarnado, cura o abogado". 
"Más vale chicha maldita que agua bendita".

"De lo bendito solo un poquito".

Para finalizar he escogido el siguiente pensamiento del sabio popular: "Cada uno en su casa y Dios en la de todos".

Si entendemos esta frase en sentido literal, en la primera parte de ella, cada familia aparece ocupada en sus asuntos, los que comprometen a los miembros del clan. Así se puede concebir una sociedad individualista y no solidaria, que carecería de un vínculo para una convivencia pacífica y fructífera. Por eso, la segunda parte perfecciona esa convivencia. Si Dios, con todo lo que implica para el sabio popular, está realmente en nuestra casa y en la de todos, todos los miembros de esa comunidad ven el mundo alumbrado por la misma luz. Tanto más si aquí la palabra "casa" es una metáfora de la persona.

No siempre nuestro sufrido pueblo vivió, como ahora, hacinado en poblaciones marginales, en suburbios desoladores o en bloques de concreto que más parecen sepulcros colectivos que casa habitación, desarraigado de la tierra y de la sabiduría de sus ancestros. Nuestros antropólogos, desde el siglo xix, han hallado en el texto hablado de sus abuelos palabras de auténtica verdad, como las que hemos escuchado hoy al pasar, cuya sencillez esconde mucha profundidad en el pensar y en el sentir. Por eso, si no podemos volver el tiempo hacia atrás, al menos esforcémonos por conocer lo que ha quedado de ese legado de sapiencia para incorporarlo a la educación superior debidamente procesado, para que nuestros alumnos lleguen a saber que hubo en los campos de Chile ciertos filósofos de humilde origen, quienes, a su manera, reflexionaron también sobre los tres temas fundamentales de la filosofía tradicional: el hombre, el mundo y Dios. 